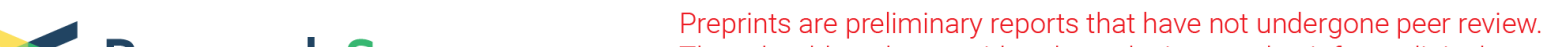 $\begin{array}{ll}\text { Research Square } & \text { They should not be considered conclusive, used to inform clinical practice, } \\ \text { or referenced by the media as validated information. }\end{array}$
}

\section{The Paris System for Reporting Urinary Cytology Improves the Negative Predictive Value of High- grade Urothelial Carcinoma}

\section{Mari Yamasaki}

Department of Urology, Faculty of Medicine, Kagawa University

Rikiya Taoka ( $\nabla$ taoka.rikiya@kagawa-u.ac.jp)

Department of Urology, Faculty of Medicine, Kagawa University

\section{Kazuya Katakura}

Department of Diagnostic Pathology, University Hospital, Faculty of Medicine, Kagawa University

\section{Toru Matsunaga}

Department of Diagnostic Pathology, University Hospital, Faculty of Medicine, Kagawa University

Naoya Kani

Department of Urology, Faculty of Medicine, Kagawa University

\section{Tomoko Honda}

Department of Urology, Faculty of Medicine, Kagawa University

\section{Satoshi Harada}

Department of Urology, Faculty of Medicine, Kagawa University

\section{Yoichiro Tohi}

Department of Urology, Faculty of Medicine, Kagawa University

\section{Yuki Matsuoka}

Department of Urology, Faculty of Medicine, Kagawa University

\section{Takuma Kato}

Department of Urology, Faculty of Medicine, Kagawa University

\section{Homare Okazoe}

Department of Urology, Faculty of Medicine, Kagawa University

\section{Hiroyuki Tsunemori}

Department of Urology, Faculty of Medicine, Kagawa University

\section{Nobufumi Ueda}

Department of Urology, Faculty of Medicine, Kagawa University

\section{Reiji Haba}

Department of Diagnostic Pathology, University Hospital, Faculty of Medicine, Kagawa University

\section{Mikio Sugimoto}

Department of Urology, Faculty of Medicine, Kagawa University 


\section{Research Article}

Keywords: urothelial carcinoma, high-grade urothelial carcinoma, urine cytology, The Paris System for Reporting Urinary Cytology, negative predictive value

Posted Date: February 2nd, 2022

DOl: https://doi.org/10.21203/rs.3.rs-1234637/v1

License: (c) (i) This work is licensed under a Creative Commons Attribution 4.0 International License. Read Full License

Version of Record: A version of this preprint was published at BMC Urology on April 5th, 2022. See the published version at https://doi.org/10.1186/s12894-022-01005-8. 


\section{Abstract}

Background: The Paris System (TPS) for reporting urinary cytology differs from conventional systems (CS) in that it focuses on the diagnosis of high-grade urothelial carcinoma (HGUC). This study investigated the impact of TPS implementation on the diagnostic accuracy of HGUC by comparing it with CS.

Methods: A total of 649 patients who underwent transurethral resection of bladder tumor (TURBT) between January 2009 and December 2020 were included in this study. Our institution adopted TPS to report urinary cytology in February 2020. The diagnostic accuracy of HGUC in preoperative urinary cytology was compared with the presence or absence of HGUC in resected specimens of TURBT before and after TPS implementation.

Results: After implementing TPS in urinary cytology, 89 patients were reviewed and compared with 560 patients whose urinary cytology was diagnosed by CS. TPS and CS for detecting HGUC had $56.0 \%$ and $58.2 \%$ sensitivity, $97.8 \%$ and $91.2 \%$ specificity, and $93.3 \%$ and $87.9 \%$ positive predictive values, respectively. There were no significant differences between TPS and CS in terms of sensitivity, specificity, and positive predictive value for HGUC $(P=0.83,0.21,1.00)$. On the other hand, the negative predictive value for HGUC using TPS was $80.0 \%$, which was significantly higher than that of CS $(66.4 \%, P=0.04)$ The multivariate logistic regression analysis indicated that not using TPS was one of the independent predictive factors associated with false-negative results for HGUC (odds ratio, 2.26; $95 \%$ confidence interval, 1.08-4.77; $P=0.03)$.

Conclusion: In instances where urinary cytology is reported as negative for HGUC by TPS, there is a low probability of HGUC, indicating that TPS has a potential diagnostic benefit.

\section{Background}

Based on the latest Global Cancer Incidence, Mortality And Prevalence data, bladder cancer (BC) is the 10th most common form of cancer worldwide, with an estimated 573,000 new cases in 2020 [1]. Approximately $75 \%$ of newly diagnosed BC cases are non-muscle-invasive BC (NMIBC) [2]. In clinical practice, NMIBC is treated with transurethral resection of bladder tumor (TURBT) followed by intravesical therapy, depending on the risk of recurrence and progression [3]. However, NMIBC recurs in approximately $50 \%$ of the cases [2]. Therefore, patients with NMIBC need surveillance using regular cystoscopy and urinary cytology for at least 5 years after the initial treatment [3].

Some histological types of BC contain pathologically different properties with varying clinical courses. In 2004, the World Health Organization/ International Society of Urological Pathology consensus classification system for papillary urothelial neoplasms of the urinary bladder was published [4]. The system classifies urothelial cancer (UC) into two main types: low-grade UC (LGUC) and high-grade UC (HGUC) [5]. Clinically, although LGUC has a low malignant potential, HGUC has a risk of disease 
progression and metastases, followed by death $[6,7]$. Therefore, HGUC cannot be ignored in patients with $\mathrm{BC}$.

Urinary cytology is a convenient screening tool for UC $[3,8]$. However, the terminology for reporting urinary cytology has not been standardized. The Paris System (TPS) for reporting urinary cytology is a recently established international system for diagnosing urinary tract cytology specimens [9]. TPS differs from conventional systems (CS) in that it focuses on the diagnosis of HGUC. Effective detection of HGUC, which has the potential to progress and metastasize, is crucial for patients with suspected HGUC of the bladder. Therefore, TPS, which focuses on the diagnosis of HGUC, may benefit patients more than CS [10, 11]. However, there are few reports on the use TPS for HGUC detection. This study, therefore, aimed to reveal the impact of TPS implementation for urinary cytology diagnosis on the diagnostic accuracy of HGUC in real clinical situations by comparing it with CS.

\section{Methods}

\section{Study population and design}

From January 2009 to December 2020, 755 patients underwent TURBT at Kagawa University Hospital. Of these, 21 patients who were pathologically diagnosed with non-urothelial malignancies and 85 patients whose urinary cytology had not been evaluated before TURBT were excluded. A total of 649 patients were included in the study. Our institution adopted TPS to report urinary cytology in February 2020. Before that, we used CS using the Papanicolaou-stained urinary cytology system. The included patients were divided into two groups of 89 patients and 560 patients each, who used TPS or CS to report urinary cytology, respectively.

Urine specimens were used as voided urine samples on the day before TURBT. The CS has five classes: class 1 , inadequate or absence of suspicious cells; class 2, atypical cells but not malignant; class 3 , cells suspected of being malignant but not confidently; class 4, suspected malignant cells; and class 5 , malignant cells. We defined the criteria that positive urinary cytology was greater than class 4 , and negative urinary cytology was classified as class 1 or 2 in the CS. On the other hand, TPS requires four categories for reporting urinary cytology: negative for HGUC (NHGUC), atypical urothelial cell, suspicious for HGUC (SHGUC), and HGUC. This study defined SHGUC and HGUC as positive urinary cytology and NHGUC as negative urinary cytology in TPS. We retrospectively compared the positive or negative results of preoperative urinary cytology in the presence or absence of HGUC in resected specimens of TURBT.

\section{Data collection}

In addition to reports of histopathological diagnosis of the resected specimen and preoperative urinary cytology, age, sex, prior recurrence status, tumor appearance, tumor number, largest tumor diameter, tumor grade, pathological T-stage, and presence of carcinoma in situ (CIS) were retrospectively investigated. This study was conducted according to the principles outlined in the Declaration of Helsinki 
(as revised in Fortaleza, Brazil, October 2013), and these surveys were performed with the approval of the Ethics Committee of Kagawa University (permission number: 2020-070). The need for informed consent was waived by the Ethics Committee, Faculty of Medicine, Kagawa University because of the retrospective nature of this study.

\section{Statistical analysis}

The diagnostic accuracy of HGUC was calculated as the sensitivity, specificity, negative predictive value (NPV), and positive predictive value (PPV). The Mann-Whitney $U$ test or Fisher's exact test was used to compare the clinical characteristics and diagnostic accuracy index between TPS and CS groups. Multivariate analysis with a logistic regression model was performed to determine an independent predictive factor for NPV errors. The number of variables incorporated into the multivariate analysis was determined based on the number of events. All statistical analyses were performed using SPSS for Windows version 12 (SPSS Inc., Chicago, IL, USA). Statistical significance was set at $P<0.05$.

\section{Results}

\section{Patient characteristics}

Data from a total of 89 patients diagnosed with BC after implementing TPS were reviewed and compared with 560 patients whose urinary cytology was diagnosed by CS. Table 1 shows the patients' characteristics in TPS and CS groups. The proportion of primary BC was higher in the TPS group than in the CS group ( $76.4 \%$ vs. $60.5 \%, P<0.01)$. In addition, the proportion of TURBT history within 90 days, including the second TURBT in the TPS group, was higher than that of the CS group (30.3\% vs. $14.6 \%$, $P<0.01)$. Furthermore, the TPS group had a larger tumor size than the $C S$ group $(P=0.05)$. By contrast, there were no significant differences in age, sex, tumor appearance, tumor number, presence of highgrade tumor, pathological tumor stage, and presence of CIS between the two groups.

Table 1. Patient characteristics 


\begin{tabular}{|c|c|c|c|c|c|}
\hline Variables & & & $\begin{array}{c}\text { CS } \\
(n=560)\end{array}$ & $\begin{array}{c}\text { TPS } \\
(n=89)\end{array}$ & P-values* \\
\hline Mean age & & years (range) & $73.1(31-100)$ & $73.5(26-93)$ & 0.39 \\
\hline Sex & Male & no. $(\%)$ & $487(87.0)$ & $77(86.5)$ & 0.91 \\
\hline Prior recurrence status & $\begin{array}{l}\text { Female } \\
\text { Primary } \\
\text { Recurrent }\end{array}$ & $\begin{array}{l}\text { no. }(\%) \\
\text { no. }(\%) \\
\text { no. }(\%)\end{array}$ & $\begin{array}{r}73(13.0) \\
339(60.5) \\
221(39.5)\end{array}$ & $\begin{array}{l}12(13.5) \\
68(76.4) \\
21(23.6)\end{array}$ & $<0.01$ \\
\hline Prior TUR within 90 days & $\begin{array}{l}\text { Yes } \\
\text { No }\end{array}$ & $\begin{array}{l}\text { no. }(\%) \\
\text { no. }(\%)\end{array}$ & $\begin{array}{r}82(14.6) \\
478(85.4) \\
\end{array}$ & $\begin{array}{l}27(30.3) \\
62(69.7)\end{array}$ & $<0.01$ \\
\hline Tumor appearance & $\begin{array}{l}\text { Papillary } \\
\text { Solid }\end{array}$ & $\begin{array}{l}\text { no. }(\%) \\
\text { no. }(\%)\end{array}$ & $\begin{array}{r}478(85.4) \\
82(14.6) \\
\end{array}$ & $\begin{array}{l}78(87.6) \\
11(12.4)\end{array}$ & 0.57 \\
\hline Tumor number & $\begin{array}{l}\text { Solitary } \\
\text { Multiple }\end{array}$ & $\begin{array}{l}\text { no. }(\%) \\
\text { no. }(\%)\end{array}$ & $\begin{array}{l}389(69.5) \\
171(30.5)\end{array}$ & $\begin{array}{l}58(65.1) \\
31(34.9)\end{array}$ & 0.42 \\
\hline Largest tumor diameter & $\begin{array}{l}<3 \mathrm{~cm} \\
\geq 3 \mathrm{~cm}\end{array}$ & $\begin{array}{l}\text { no. }(\%) \\
\text { no. }(\%)\end{array}$ & $\begin{array}{c}532(95.0) \\
28(5.0) \\
\end{array}$ & $\begin{array}{r}80(89.9) \\
9(10.1) \\
\end{array}$ & 0.05 \\
\hline High-grade tumor & $\begin{array}{l}\text { Yes } \\
\text { No }\end{array}$ & $\begin{array}{l}\text { no. }(\%) \\
\text { no. }(\%)\end{array}$ & $\begin{array}{l}313(55.9) \\
247(44.1)\end{array}$ & $\begin{array}{l}42(47.2) \\
47(52.8)\end{array}$ & 0.13 \\
\hline $\begin{array}{l}\text { Pathological tumor stage } \\
\text { ( } \text { pT0 vs pT+) }\end{array}$ & $\begin{array}{l}\text { pT0 } \\
\text { pTis } \\
\text { pTa } \\
\text { pT1 } \\
\text { ə pT2 }\end{array}$ & $\begin{array}{l}\text { no. }(\%) \\
\text { no. }(\%) \\
\text { no. }(\%) \\
\text { no. }(\%) \\
\text { no. }(\%)\end{array}$ & $\begin{array}{c}108(19.2) \\
49(8.8) \\
243(43.4) \\
117(20.9) \\
43(7.7)\end{array}$ & $\begin{array}{c}25(28.1) \\
8(9.0) \\
31(34.8) \\
16(18.0) \\
9(10.1) \\
\end{array}$ & 0.06 \\
\hline Concomitant ClS & $\begin{array}{l}\text { Yes } \\
\text { No }\end{array}$ & $\begin{array}{l}\text { no. }(\%) \\
\text { no. }(\%)\end{array}$ & $\begin{array}{l}120(21.4) \\
440(78.6)\end{array}$ & $\begin{array}{l}18(20.2) \\
71(79.8)\end{array}$ & 0.79 \\
\hline
\end{tabular}

$C S=$ conventional systems, TPS=The Paris System, TUR=transurethral resection, CIS= carcinoma in situ

${ }^{*} P$-values were estimated using using the Mann-Whitney $U$ test or the Fisher's exact test.

\section{Urinary cytology and histopathological diagnosis}

Table 2 shows a summary of the urinary cytology and histopathological diagnoses for each TPS and CS group. The proportion of patients who were diagnosed with SHGUC and HGUC in the TPS group was $16.9 \%$, which was significantly lower than that of patients with positive urinary cytology in the CS group (26.6\%, $\mathrm{P}=0.04)$. Of 560 patients in the CS group, 313 (55.9\%) were histologically diagnosed with HGUC in the resected specimens. Of those, 94 (30.0\%) patients who were diagnosed with negative urinary cytology were false-negative, and 131 (41.9\%) patients with positive urinary cytology were truly positive. In contrast, of 89 patients in the TPS group, 42 (47.2\%) were histologically diagnosed with HGUC. Of these, $11(26.2 \%)$ patients whose urinary cytology was diagnosed as NHGUC by TPS had false-negative results, and 14 (33.3\%) patients with positive urinary cytology were truly positive.

Table 2. Summary of cytological and histopathological diagnoses 


\begin{tabular}{llcccc} 
& Variables & Negative & LGUC & HGUC & total \\
\cline { 2 - 6 } CS & class 1 & 16 & 31 & 11 & $58(10.4)$ \\
& class 2 & 63 & 76 & 83 & $222(39.6)$ \\
& class 3 & 19 & 24 & 88 & $131(23.4)$ \\
& class 4 & 2 & 3 & 32 & $37(6.6)$ \\
& class 5 & 8 & 5 & 99 & $112(20.0)$ \\
\hline \multirow{4}{*}{ total } & $108(19.3)$ & $139(24.8)$ & $313(55.9)$ & $560(100.0)$ \\
\hline TPS & NHGUC & 23 & & & \\
& AUC & 1 & 1 & 11 & $55(61.8)$ \\
& SHGUC & 0 & 0 & 17 & $19(21.3)$ \\
& HGUC & 1 & 0 & 11 & $3(3.4)$ \\
\hline & total & $25(28.1)$ & $22(24.7)$ & $42(47.2)$ & $89(100.0)$
\end{tabular}

Data was shown in no. or no(\%).

CS=conventional systems, TPS=The Paris system, LGUC=low-grade urothelial carcinoma, HGUC=high-grade urothelial carcinoma, NHGUC=negative for high-grade urothelial carcinoma, $A U C=$ atypical urothelial cells, SHGUC=suspicious for high-grade urothelial carcinoma, HGUC=high-grade urothelial carcinoma

\section{Sensitivity, specificity, PPV, and NPV of urine cytology for HGUC}

Table 3 summarizes the detection of HGUC in TPS and CS groups. There were no significant differences between TPS and CS groups in terms of sensitivity, specificity, and PPV for HGUC. Contrastingly, the TPS group had a significantly higher NPV for HGUC than the CS group $(80.0 \% \mathrm{vs.} 66.4 \%, P=0.04)$. A total of 105 patients had false-negative urinary cytology results for HGUC.

Table 3. The detection ability of high-grade urothelial carcinoma

\begin{tabular}{llccc} 
& & CS & TPS & P-values $^{*}$ \\
\hline Sensitivity & $(\%)$ & 58.2 & 56.0 & 0.83 \\
Specificity & $(\%)$ & 91.2 & 97.8 & 0.21 \\
PPV & $(\%)$ & 87.9 & 93.3 & 1.00 \\
NPV & $(\%)$ & 66.4 & 80.0 & 0.04 \\
\hline
\end{tabular}

CS \& TPS=Conventional \& The Paris systems for reporting urinary cytology, $P P V \& N P V=$ positive \& negative predictive value.

${ }^{*} P$-value was estimated using the Fisher's exact test.

Multivariate logistic regression analysis, which included prior recurrence status, prior TURBT within 90 days, and intraoperative factors such as tumor appearance, tumor number, and largest tumor diameter, revealed that not using TPS was an independent predictive factor associated with false-negative results for HGUC (odds ratio, 2.26; 95\% confidence interval, 1.08-4.77; $P=0.03$; Table 4).

Table 4. Multivariate analysis for the prediction of false-negatives for high-grade urothelial carcinoma 


\begin{tabular}{lccc} 
& \multicolumn{3}{c}{ Multivariate } \\
\cline { 2 - 4 } Variables & ORs $^{*}$ & $95 \% \mathrm{Cl}$ & P-values $^{*}$ \\
\hline No use of TPS & 2.26 & $1.08-4.77$ & 0.03 \\
Prior recurrence status & 0.47 & $0.27-0.79$ & $<0.01$ \\
Prior TUR within 90 days & 0.71 & $0.36-1.38$ & 0.31 \\
Mutiple tumor & 1.59 & $0.91-2.78$ & 0.11 \\
Solid tumor & 1.99 & $1.03-5.00$ & $<0.01$ \\
Large tumor $(\geq 3 \mathrm{~cm})$ & 2.27 & $0.49-8.07$ & 0.33 \\
\hline
\end{tabular}

$\mathrm{Cl}=$ confidence, $\mathrm{OR}=$ odds ratio, $\mathrm{CS}=$ conventional systems, $T P S=$ The Paris system,

$T U R=$ transurethral resection

${ }^{*} \mathrm{O} R$ and $p$-value were estimated using multivariate logistic regression analysis.

\section{Discussion}

TPS was created as an international form to standardize the reporting of urinary cytology [9]. TPS differs from CS in that it focuses on the diagnosis of HGUC. However, there are few reports on the ability of TPS to detect HGUC. This study compared TPS and CS with regards to detecting HGUC in urine specimens before tumor resection and in resected tumor tissues. The results indicated that TPS was superior to CS in terms of its NPV for HGUC. HGUC is well known to be associated with a worse overall survival. Therefore, a high NPV for HGUC using TPS is clinically important for patients with suspected BC.

Urinary cytology is typically used to screen for UC in two clinical situations: when new-onset UC is suspected, such as in patients with unexplained hematuria, and during surveillance after BC treatment [12]. In particular, clinical guidelines suggest that cystoscopy is needed for at least 5 years for patients with a history of $B C$ because half of the patients with $B C$ will have an intravesical recurrence $[2,3]$. However, cystoscopy is associated with physical pain and mental burden [13] which some patients experience during urinary tract infections [14]. If the high NPV of TPS can deny the presence of HGUC, and reduce additional examinations such as cystoscopy, it may improve patient quality of life and costeffectiveness.

TPS defines standardized cytomorphologic and numerical criteria for its diagnostic categories, which stratify a patient's risk for HGUC [9]. In other words, strict definitions of TPS may reduce the sensitivity of HGUC. In this study, $16.9 \%$ of patients were diagnosed with SHGUC and HGUC in the TPS group, which was significantly lower than that of patients with positive urinary cytology in the CS group. However, there was no difference in the sensitivity for HGUC between the TPS and CS groups. Recent reports demonstrated that the sensitivity for HGUC using TPS ranged from 83.3-87.1\% $[11,15,16]$. In addition, the NPV was between $81.4 \%$ and $86.4 \%$, which was similar to the value obtained in this study $(80.0 \%)$. These data demonstrate that TPS can reduce the rate of unnecessary indeterminate diagnoses while maintaining excellent sensitivity for identifying HGUC.

Multivariable logistic regression analysis indicated that TPS may reduce false-negative results for HGUC. At the same time, recurrent tumors also reduced false-negatives for HGUC. Lee et al. analyzed the causes of false-negative cytology in HGUC cases [17]. The possible explanations were the overestimation of the grade by the pathologist and inflammation of the bladder. In this study, inflammation due to prior 
transurethral surgery and subsequent intravesical instillation therapy may have affected the diagnosis of urinary cytology. However, solid tumors were found to be at risk of false-negatives for HGUC. The relationship between solid tumors and false-negatives for HGUC may have been influenced by the smaller area of the tumor surface compared to papillary tumors. Although a certain number of false negatives for HGUC are expected, serial urinary cytology may decrease false-negative results and improve sensitivity for detection [18]. Therefore, in clinical practice, TPS should be used for urinary cytology because it yields fewer false-negative results than CS.

One of this study's limitations is that cytological findings were interpreted by a single pathologist. Of course, the accuracy of the diagnosis has been re-evaluated by another pathologist. However, differences in the diagnosis of urinary cytopathology between pathologists have been reported [19]. Therefore, further studies addressing interobserver variability should be conducted. In addition, urine collection methods, urine collection volumes, and urinary cell counts can affect the diagnostic quality of urinary cytology [9]. Since there was no information on urine specimens in this study, the effect of urine specimens on urinary cytology could not be investigated. The study's retrospective nature was an additional limitation. However, to the best of our knowledge, this is the first study to consider various factors affecting the quality of urinary cytology, and demonstrate that the implementation of TPS in clinical practice may improve the NPV for HGUC.

\section{Conclusions}

Our study revealed the impact of TPS implementation on the diagnostic accuracy of HGUC in real clinical situations by comparing it with CS. As a result, this study clearly indicates that, in instances where urinary cytology is reported as NHGUC by TPS, there is a low probability of HGUC. These results support the implementation of the TPS in clinical practice.

\section{List Of Abbreviations}

CIS, carcinoma in situ; UC, urothelial carcinoma; TPS, the Paris System; LGUC, low-grade urothelial carcinoma; HGUC, high-grade urothelial carcinoma; CS, conventional systems; NPV, negative predictive value; PPV, positive predictive value; TURBT, transurethral resection of bladder tumor; SHGUC, suspicious for high-grade urothelial carcinoma; NHGUC, negative for high-grade urothelial carcinoma; BC, bladder cancer; NMIBC, non-muscle-invasive bladder cancer

\section{Declarations}

\section{Ethics approval and consent to participate}

This study was conducted according to the principles outlined in the Declaration of Helsinki (as revised in Fortaleza, Brazil, October 2013), and these surveys were performed with the approval of the Ethics Committee of Kagawa University (permission number: 2020-070). The need for informed consent was 
waived by the Ethics Committee, Faculty of Medicine, Kagawa University because of the retrospective nature of this study.

\section{Consent for publication}

Not applicable.

\section{Availability of data and materials}

The dataset generated and/or analyzed during the current study is not publicly available due to identifiable patient information but is available from the corresponding author upon reasonable request.

\section{Competing interests}

The authors declare that they have no competing interest

\section{Funding}

No funding or grants were provided for this study.

\section{Authors' contributions}

All the authors participated in the study design. MY and RT interpreted the data, performed statistical analyses, and wrote the manuscript. KK and TM contributed to the implementation of TPS and pathological diagnosis. RH and MS supported the original concept and design of this study. $\mathrm{NK}, \mathrm{TH}, \mathrm{SH}$, YT, YM, TK, HO, HT, and NU critically revised the manuscript. All authors read and approved the final manuscript.

\section{Acknowledgments}

The authors would like to thank Editage (www.editage.jp) for English language editing.

\section{References}

1. Sung H, Ferlay J, Siegel RL, Laversanne M, Soerjomataram I, Jemal A, et al. Global Cancer Statistics 2020: GLOBOCAN Estimates of incidence and mortality Worldwide for 36 Cancers in 185 Countries. CA Cancer J Clin. 2021;71:209-49.

2. Abraham J, Gulley JL. The Bethesda Handbook of Clinical Oncology. 5th ed. Philadelphia: Wolters Kluwer Health; 2019.

3. Babjuk M, Burger M, Capoun O, Cohen D, Compérat EM, Dominguez Escrig JL, et al. European Association of Urology guidelines on non-muscle-invasive bladder cancer (ta, T1, and carcinoma in situ). Eur Urol. 2022;81:75-94.

4. Eble JN, Sauter G, Epstein JI. World Health Organization classification of tumours. Pathology and Genetics of Tumours of the Urinary System and Male Genital Organs. Lyon: IARC Press, 2004. 
5. Miyamoto H, Miller JS, Fajardo DA, Lee TK, Netto GJ, Epstein JI. Non-invasive papillary urothelial neoplasms: The 2004 WHO/ISUP classification system. Pathol Int. WHO. 2010;60:1-8.

6. Kamat AM, Hahn NM, Efstathiou JA, Lerner SP, Malmström PU, Choi W, et al. Bladder cancer. Lancet. 2016;388:2796-810.

7. Knowles MA, Hurst CD. Molecular biology of bladder cancer: New insights into pathogenesis and clinical diversity. Nat Rev Cancer. 2015;15:25-41.

8. Brown FM. Urine cytology. It is still the gold standard for screening? Urol Clin North Am. 2000;27:2537.

9. Rosenthal DL, Wojcik EM, Kurtycz DFI. The Paris System for Reporting Urinary Cytology. New York: Springer; 2016.

10. Cowan ML, Rosenthal DL, VandenBussche CJ. Improved risk stratification for patients with highgrade urothelial carcinoma following application of the Paris System for Reporting Urinary Cytology. Cancer Cytopathol. 2017;125:427-34.

11. Meilleroux J, Daniel G, Aziza J, d'Aure DM, Quintyn-Ranty ML, Basset CM, et al. One year of experience using the Paris System for Reporting Urinary Cytology. Cancer Cytopathol. 2018;126:4306.

12. VandenBussche CJ. A review of the Paris system for reporting urinary cytology. Cytopathology. 2016;27:153-6.

13. Jung A, Nielsen ME, Crandell JL, Palmer MH, Bryant AL, Smith SK, et al. Quality of life in non-muscleinvasive bladder cancer survivors: A systematic review. Cancer Nurs. 2019;42:E21-33.

14. Sullivan NM, Sutter VL, Mims MM, Marsh VH, Finegold SM. Clinical aspects of bacteremia after manipulation of the genitourinary tract. J Infect Dis. 1973;127:49-55.

15. Rai S, Lali BS, Venkataramana CG, Philipose CS, Rao R, Prabhu GL. A quest for accuracy: Evaluation of the Paris system in diagnosis of urothelial carcinomas. J Cytol. 2019;36:169-73.

16. Stanzione N, Ahmed T, Fung PC, Cai D, Lu DY, Sumida LC, et al. The continual impact of the Paris System on urine cytology, a 3-year experience. Cytopathology. 2020;31:35-40.

17. Lee PJ, Owens CL, Lithgow MY, Jiang Z, Fischer AH. Causes of false-negative for high-grade urothelial carcinoma in urine cytology. Diagn Cytopathol. 2016;44:994-9.

18. VandenBussche CJ, Rosenthal DL, Olson MT. Adequacy in voided urine cytology specimens: The role of volume and a repeat void upon predictive values for high-grade urothelial carcinoma. Cancer Cytopathol. 2016;124:174-80.

19. Olson MT, Boonyaarunnate T, Aragon Han P, Umbricht CB, Ali SZ, Zeiger MA. A tertiary center's experience with second review of 3885 thyroid cytopathology specimens. J Clin Endocrinol Metab. 2013;98:1450-7. 